\title{
A extensão universitária em debate: 0 curso pré-universitário como espaço de educação popular
}

\author{
The university extension in debate: the pre-university course as a space for popular education
}

\author{
Thiago Ingrassia Pereira* \\ Tatiane Fernanda Gomes
}

\section{Resumo}

\begin{abstract}
Integrante do eixo que caracteriza a universidade brasileira junto com a pesquisa e o ensino, a extensão potencializa a relação da educação superior com a comunidade. O estudo em tela aborda as potencialidades de cursos pré-universitários populares em processos de aprendizagem, formação inicial de docentes e diálogo entre a universidade e sujeitos sociais diversos. Objetiva discutir a extensão universitária a partir de uma experiência de curso pré-universitário vinculada ao desafio da democratização do acesso à universidade. Embasado em princípios da educação popular de matriz freireana e em estudos e pesquisas sobre educação, universidade e extensão, este trabalho situa historicamente a extensão como uma prática dialógica, permeada por intencionalidade política, com desdobramentos epistemológicos e metodológicos no conhecimento acadêmico. Por meio de grupos focais com estudantes universitários(as) que atuam como educadores(as) em curso pré-universitário, a pesquisa desenvolvida explora as diferentes contribuições desse espaço para a formação docente e em processos de conscientização mais amplos que potencializam a reinvenção da universidade, tendo compromisso com cenários de transformação social. Dessa forma, sinaliza para o potencial de projetos de extensão universitária como mecanismos de produção e difusão de conhecimento emancipatório.
\end{abstract}

Palavras-chave: Extensão universitária. Pré-universitário popular. Educação popular.

\section{Abstract}

As part of the axis that characterizes the brazilian university along with research and teaching, the extension enhances the relationship of higher education with the community. The on-screen study addresses the potential of popular pre-university courses in learning processes, initial teacher training and dialogue between the university and various social subjects. It aims to discuss university extension based on a pre-university course experience linked to the challenge of democratizing access to university. Based on principles of popular education of Freirean origin and in studies and research on education, university and extension, this work historically places extension as a dialogical practice, permeated by political intentionality with epistemological and methodological developments in academic knowledge. Through focus groups with university students that act as pre-university educators, the research developed explores the different contributions of this space to teacher education and in wider awareness processes that enhance the reinvention of the university, having a commitment to scenarios of social transformation. In this way, it signals to the potential of university extension projects as mechanisms of production and diffusion of emancipatory knowledge.

Keywords: Popular education. Popular pre-university. University extension.

\author{
Recebido em 28/03/2018 - Aprovado em 17/06/2018 \\ http://dx.doi.org/10.5335/rep.v25i3.8570
}

Doutor em Educação (UFRGS). Professor adjunto da Universidade Federal da Fronteira Sul (UFFS), campus Erechim. Atua no Programa de Pós-Graduação Profissional em Educação (PPGPE/UFFS), mestrado profissional em Educação, e no Programa de Pós-Graduação Interdisciplinar em Ciências Humanas (PPGICH/UFFS), mestrado acadêmico. E-mail: thiago.ingrassia@gmail.com

** Mestre em Educação (UFFS). Servidora técnico-administrativa em Educação na Universidade Federal de Santa Maria (UFSM). E-mail: tatiane@ufsm.br 


\section{Introdução}

A universidade brasileira é uma instituição recente no contexto ocidental, aproximando-se de um século de existência dentro da quase milenar trajetória universitária (ROSSATO, 2005). Apresenta singularidade no contexto latino-americano, pois, diferentemente da colonização espanhola, Portugal constrangeu a construção de universidades em sua colônia. Isso explica o fato de, em análise comparada, o Brasil ter uma universidade tardia ou temporã (CUNHA, 1985).

Em uma sociedade estruturalmente desigual como a brasileira, a relação entre a universidade e a sociedade ocorre por meio de tensões que revelam uma problemática trajetória no tocante à inclusão dos segmentos populares em sua estrutura acadêmica. $\mathrm{O}$ elitismo da universidade brasileira é um aspecto histórico forjado no sistema social que concentra tanto capital econômico como cultural.

Ao longo do século XX, a universidade brasileira foi configurando sua estrutura por meio da influência de modelos originários de experiências europeias e estadunidense (SGUISSARDI, 2011). A identidade da instituição foi sendo construída pelo embate de grupos de seu interior, bem como, de forma progressiva, pela reivindicação de sujeitos sociais que passaram a disputá-la como espaço de ascensão social. É o que verificamos no contexto das reformas de base no início dos anos 1960, quando a reforma universitária, em muito inspirada pelo Movimento de Córdoba de 1918, entrou na pauta por meio da União Nacional dos Estudantes (PINTO, 1994).

Após o período da Ditadura Militar, pós-Golpe de 1964, a influência dos Estados Unidos na configuração universitária nacional foi visível com a Reforma de 1968. Formou-se, em grande medida, uma instituição tecnocrática em que "a racionalização, a eficiência e a produtividade tornam-se valores absolutos: têm validade em si e por si mesmos" (ROMANELLI, 2012, p. 241). O legado desse processo é a construção de uma universidade reservada aos estratos médios e superiores da sociedade, detentores dos capitais necessários ao prolongamento da vida escolar.

Com o final do período de governos militares, há um quadro de reorganização administrativa do país em meio a cenário de efervescência social. A educação é uma das bandeiras de mobilização dos sujeitos sociais organizados e marca presença no texto constitucional de 1988. No que concerne à universidade, o artigo 2017 da Constituição federal define: "as universidades gozam de autonomia didático-científica, administrativa e de gestão financeira e patrimonial, e obedecerão ao princípio de indissociabilidade entre ensino, pesquisa e extensão" (BRASIL, 1988, não paginado).

Neste artigo, o eixo da extensão universitária é o foco analítico. Para tanto, além de breve contextualização do sistema universitário brasileiro e do exame de 
seus condicionantes econômicos, políticos e culturais, apresenta-se a experiência de um projeto de extensão envolvendo um curso pré-universitário popular. O principal objetivo é refletir sobre o pré-universitário como um espaço de educação popular revestido de potencialidade formativa para novos(as) docentes, além de ser um mecanismo extensionista capaz de aproximar a sociedade da universidade.

Este trabalho é um recorte de pesquisa desenvolvida em nível de mestrado profissional em Educação e adota o referencial da educação popular de matriz freireana, considerando as experiências concretas e intersubjetivas dos sujeitos envolvidos no projeto de extensão. Os dados empíricos examinados são provenientes de grupos focais realizados em 2016, no universo do curso Pré-Universitário Popular Alternativa (Pupa), projeto de extensão da Universidade Federal de Santa Maria (UFSM).

\section{Dialogando sobre extensão universitária e educação}

Considerando a perspectiva teórica da educação popular presente na obra de Paulo Freire, é interessante discutir o conceito de extensão universitária a partir de sua problematização. A relação entre a instituição universitária e a sociedade é uma preocupação seminal da proposta educacional de Freire, fato que pode ser observado desde o final da década de 1950, na experiência do Serviço de Extensão Cultural (SEC) da então Universidade de Recife.

Nesse sentido, a extensão universitária é compreendida como uma postura diante das demandas sociais dos grupos populares. Assume, nessa perspectiva, posição radicalmente contrária à noção tradicional de extensão como alargamento da universidade, ou seja, uma ida da universidade à comunidade, como se coubesse à universidade aplicar ou ensinar seus conhecimentos aos que nela não estão.

Aliás, essa é uma abordagem importante da reflexão proposta: compreender a universidade pública ou comunitária como uma instituição também diretamente vinculada àqueles que nela não estão, mas a mantêm, direta ou indiretamente, com sua participação no fundo público ou no orçamento da instituição. Quanto a isso, é ilustrativa a posição da equipe de Paulo Freire no SEC:

entendemos que a verdadeira práxis da extensão cultural, entre nós, deva partir daí. Sua motivação afunda raízes na grande contradição da Universidade Brasileira que, entre outras coisas, põe em choque $1 \%$ da nossa população com os $99 \%$ restantes, isolados na mais completa cegueira espiritual e embrutecidos no abandono de uma forma de escravização social e econômica. Parece uma ironia que esses $99 \%$ do povo brasileiro devessem, mesmo alienados da Universidade, sustentá-la social e economicamente. Entretanto, assim o é. A extensão, por conseguinte, para ser verdadeiramente funcional, deve estar voltada para esses $99 \%$, a imensa maioria do povo brasileiro - no sentido de saldar, simplesmente, uma pesada dívida que não é apenas acidental e nem recente, porque é uma dívida histórica. Quando fazemos extensão cultural nestes termos, estamos lutando inclusive contra os erros e os vícios de nosso passado colonial (MACIEL, 1963, p. 25-26). 
Nessa linha, a extensão é compreendida tanto em sua função social como em sua contribuição à construção do conhecimento científico. Portanto, não se trata de uma dimensão da vida acadêmica desprovida do objetivo maior da universidade, que é a produção de novos conhecimentos. Pelo contrário, ao não ser apenas um alargamento da ação universitária, a extensão potencializa o espaço de diálogo entre os saberes acadêmicos e os saberes populares, realizando uma fecunda comunicação (FREIRE, 1983). Aliás, é a crítica de Freire ao termo extensão que potencializa sua compreensão filosófica. Dessa forma,

é, talvez, como num paradoxo, que a extensão universitária constituiu suas mais significativas referências e práticas, a partir da denúncia de Paulo Freire do conceito de "extensão", o que obrigou os que quiseram continuar a usar o termo a uma radical reconceitualização, que incorporou o essencial da perspectiva de Paulo Freire (PAULA, 2013, p. 18).

Assim, a extensão praticada pelo SEC nos anos 1960 está alicerçada na compreensão filosófica de valorização da cultura popular e no entendimento político acerca da educação como prática da liberdade. Mais recentemente, a extensão é pensada como parte principal de uma estratégia de aproximação da universidade e da comunidade, se constituindo em eixo de grande potencial para novas práticas epistemológicas no âmbito pluriuniversitário (FLEURI, 2009).

Numa postura mais incisiva quanto ao envolvimento da sociedade na universidade, encontramos a proposta de "ecologia de saberes", que é "um aprofundamento da pesquisa-ação. É algo que implica uma revolução epistemológica no seio da universidade e, como tal, não pode ser decretada por lei [...]. A ecologia dos saberes é, por assim dizer, uma forma de extensão ao contrário, de fora da universidade para dentro da universidade" (SANTOS, 2005a, p. 76). Dessa forma, ao falar de "ecologia", Santos nos convida a pensar a relação entre as diversas práticas e saberes que brotam da experiência.

Portanto, como parte da "sociologia das ausências" (SANTOS, 2004), a "ecologia dos saberes" é uma noção que aponta para a igualdade epistêmica entre os sujeitos sociais. Assim, aquilo que é deixado de lado pela ciência tradicional, com suas teorias hegemônicas, é trazido à tona por essa concepção, pois o objetivo é não desperdiçar a experiência. Sistematizando,

a ecologia dos saberes visa criar um novo tipo de relacionamento entre o saber científico e outras formas de conhecimento. Consiste em conceder "igualdade de oportunidades" às diferentes formas de saber envolvidas em disputas epistemológicas cada vez mais amplas, visando à maximização dos seus respectivos contributos para a construção de "outro mundo possível", isto é, de uma sociedade mais justa e mais democrática, bem como de uma sociedade mais equilibrada em relação à natureza. A questão não está em atribuir igual validade a todos os tipos de saber, mas antes em permitir uma discussão pragmática de critérios de validade alternativos, que não desqualifique a partida tudo o que não se ajusta ao cânone epistemológico da ciência moderna (SANTOS, 2005b, p. 19). 
Ao aproximar a universidade dos saberes populares, cria-se espaço para a atuação dos movimentos sociais, entendidos como sujeitos políticos relevantes na construção de alternativas de transformação social. Surge a ideia de universidades populares, sinalizando para o papel social das instituições tanto em ações de inclusão (destaque ao debate sobre as ações afirmativas) como na produção do conhecimento conectivo entre diferentes saberes.

Esse debate está posto na agenda contemporânea e encontra suas raízes no contexto latino-americano no movimento de Córdoba, Argentina, em 1918. A América espanhola tem uma larga tradição universitária, se comparada à brasileira, fato que potencializa ações políticas em países como México, Argentina e Peru, desde o início do século XX. Vale destacar que a organização estudantil em Córdoba pautou uma agenda de reformas com vistas à popularização da universidade que foi ratificada no Congresso Internacional de Estudantes, em 1921, no México (PAULA, 2013).

Dessa forma, o debate sobre a extensão universitária promove a possibilidade de que as instituições reflitam sobre suas concepções de educação, mobilizando diferentes sujeitos sociais. Carlos Rodrigues Brandão inicia $O$ que é educação (1985) afirmando que "ninguém escapa da educação", e é em diferentes espaços que ela ocorre: "Em casa, na rua, na igreja ou na escola, de um modo ou de muitos todos nós envolvemos pedaços da vida com ela: para aprender, para ensinar, para aprender-e-ensinar. Para saber, para fazer, para ser ou para conviver, todos os dias misturamos a vida com a educação" (BRANDÃO, 1985, p. 7). Fica evidente na explanação do autor que a educação se apresenta em diferentes situações da vida e das relações.

O próprio Brandão se refere à educação como algo que assume diferentes prismas: fala-se em "educações". Nessa linha, uma possibilidade de distinção de "educações" é entre informal, não formal e formal, como alguns autores que se dedicam ao campo educacional, como Maria da Glória Gohn (2006, 2010, 2011) e Moacir Gadotti (2005) já propuseram. Iniciando esta reflexão pela educação não formal, deparamo-nos com a inclinação de confundi-la com a educação informal; entretanto, uma forma simples e direta de definir educação não formal é dizer que ela abrange processos educativos que ocorrem fora do sistema oficial de ensino. Para Gohn, na educação não formal:

os espaços educativos localizam-se em territórios que acompanham as trajetórias de vida dos grupos e indivíduos, fora das escolas, em locais informais, locais onde há processos interativos intencionais (a questão da intencionalidade é um elemento importante de diferenciação) (GOHN, 2006, p. 29). 
A educação informal, por sua vez, é composta pelas aprendizagens espontâneas da vida dos indivíduos, ou seja, ocorrem sem que haja um planejamento, uma organização ou uma sistematização, pois "se desenvolvem segundo gostos, preferências, ou pertencimentos herdados" (GOHN 2006, p. 29). Tais aprendizagens ocorrem na interação cotidiana e não apresentam a intencionalidade que é característica presente tanto na educação não formal quanto na educação formal. Nesse sentido, a autora propõe a seguinte definição de educação não formal:

um processo sociopolítico, cultural e pedagógico de formação para a cidadania, entendendo o político como a formação do indivíduo para interagir com o outro em sociedade. Ela designa um conjunto de práticas socioculturais de aprendizagem e produção de saberes, que envolve organizações/instituições, atividades, meios e formas variadas, assim como uma multiplicidade de programas e projetos sociais (GOHN, 2010, p. 33).

Em tais programas ou projetos podem ser identificados os pressupostos da educação não formal destacados por Gohn (2011), indicando que neles a aprendizagem se dá por meio da prática social e emerge das experiências vivenciadas em trabalhos coletivos. Para Gadotti (2005), a educação não formal é caracterizada por ser mais difusa e, ao mesmo tempo, "menos hierárquica e menos burocrática", uma vez que "os programas de educação não-formal não precisam necessariamente seguir um sistema sequencial e hierárquico de 'progressão'. Podem ter duração variável, e podem, ou não, conceder certificados de aprendizagem” (2005, p. 2).

Outra particularidade característica da educação não formal destacada por Gadotti refere-se ao tempo de aprendizagem: de acordo com ele, a educação não formal é flexível, "respeitando as diferenças e as capacidades de cada um, de cada uma" (2005, p. 02). Essa flexibilidade também se constata nos espaços nos quais a educação não formal ocorre. $\mathrm{O}$ autor ainda menciona a amplitude desse conceito, destacando sua vinculação ao conceito de cultura, que tem como implicação: "estar ligada fortemente à aprendizagem política dos direitos dos indivíduos enquanto cidadãos e à participação em atividades grupais, sejam esses adultos ou crianças" (2005, p. 03).

É possível identificar aproximações da educação popular com a educação não formal. Ambas têm sua origem relacionada à criação de espaços educacionais alternativos, muitas vezes preocupados com a emancipação social das classes populares. Entretanto, cabe a ressalva de que, ainda que a educação não formal eventualmente se ocupe da construção da cidadania, que favorece as classes menos favorecidas, não há, obrigatoriamente, em espaços de educação não formal, compromisso com as classes populares, como bem destaca Gohn: 
Para nós há diferenças dadas, por exemplo, que a educação não formal não tem recorte de faixa social. Ao nominar uma modalidade como Popular, estou fazendo alusão à categoria povo - em sentido genérico ou específico - camadas desfavorecidas socioeconomicamente; ou estou contrapondo um dualismo - haveria uma educação popular e uma das elites ou classes e camadas mais abastadas (GOHN, 2010, p. 25).

A universidade é um espaço formal de educação que, cada vez mais, abarca e sofre o reflexo dos outros espaços educativos. Entre o formal, o não formal e o informal, há um fluxo de pessoas, experiências e relações, ora harmônicas, ora conflitivas. Potencializar essa conexão de saberes surge como um desafio inadiável da universidade do século XXI. Por isso a extensão é um espaço privilegiado para o enfrentamento desse desafio, e projetos como o do curso pré-universitário popular podem ser mecanismos eficazes.

\section{A extensão no pré-universitário popular}

Partindo do diagnóstico do elitismo da universidade brasileira, movimentos internos e externos à instituição se constituíram em espaços de denúncia e de construção de novas possibilidades de superação desse quadro excludente. Os dados oficiais (BRASIL, 2017) apontam para um crescimento nas taxas brutas e líquidas, assim como no total das matrículas, que chega atualmente a 8.052.254, representando um aumento de 62,8\% no período (2006-2016), com uma média anual de 5\% de crescimento. Mesmo diante do aumento do número de instituições públicas na última década, as de caráter privado continuam majoritárias, totalizando cerca de $75,3 \%$ (3/4) das matrículas nos cursos de graduação no país.

Dados de 2015 indicam que a taxa bruta de matrícula na educação superior ${ }^{1}$ é de $34,6 \%$, muito aquém da meta de 50\% prevista para 2024 no Plano Nacional de Educação (PNE). O percentual da taxa líquida, considerando a população de 18 a 24 anos de idade, é de 18,1\%, também bastante abaixo da meta de $33 \%^{2}$ do PNE para 2024.

Diante desse quadro, é possível entender o movimento dos pré-universitários populares e a sua relação com projetos de extensão universitária, tendo em vista que "parte significativa das experiências de PVP [pré-vestibular popular] surge de projetos liderados pelos diretórios acadêmicos e movimento estudantil" (ZAGO, 2008, p. 153). Nos cursinhos, as aulas geralmente são ministradas por estudantes de graduação e pós-graduação, sendo comum o envolvimento de outros setores da universidade. Muitas vezes, esses espaços funcionam na forma de projetos de extensão, como no caso do Pupa, projeto de extensão da UFSM desde a origem do projeto. 
Os pré-universitários populares se colocam como uma alternativa de preparação para o ingresso no ensino superior dos estudantes das classes populares, por meio da revisão dos conteúdos, mas também fomentando o questionamento desse sistema educacional excludente. A designação "popular" delimita uma das principais características que diferem cursinhos comerciais de populares. Um cursinho popular não visa ao lucro, pois, mesmo aqueles que cobram alguma taxa, revertem-na em manutenção do espaço, produção de material didático e demais despesas operacionais.

Outro elemento característico é a postura em relação ao conhecimento e às metodologias empregadas, visando à construção do conhecimento que respeite os(as) educandos(as) e seus conhecimentos prévios, em detrimento da mera memorização de conteúdos para a resolução de provas. Ou seja, para além do ingresso no ensino superior, os cursinhos populares estão comprometidos com a transformação social e com a formação crítica de todos os indivíduos que o compõem; tal formação se reflete, inclusive, na posterior atuação dos estudantes egressos de PUPs no movimento estudantil ou em diversas representações durante a vida acadêmica, incluindo o retorno ao cursinho na condição de educadores ou coordenadores.

Na maior parte dos casos, o(a) educador(a) popular é um(a) estudante universitário(a) ou um profissional recém-formado(a), que se dispõe a trabalhar voluntariamente ou com apenas ajuda de custo. Entretanto, cabe observar: o grupo de educadores(as) de um cursinho popular, por ser diverso, não exclui a participação de sujeitos com diferentes visões políticas, ou diferentes objetivos pessoais, que fogem da democratização do acesso ao ensino superior ou da militância por um mundo menos desigual e injusto.

Uma evidente contradição permeia os cursinhos populares, pois eles se colocam entre a não aceitação do modelo meritocrático de ingresso à educação superior, que privilegia os candidatos com mais condições financeiras de buscarem preparação em cursos privados, apresentando-se como opção aos menos favorecidos, mediante a oferta de um curso preparatório. Ou seja, mesmo questionando a elitização do ensino superior, buscam auxiliar estudantes de origem popular a ingressar nele, efetivando um "duplo movimento", no qual a preparação para as provas de ingresso acontece junto com discussões críticas sobre a realidade social (PEREIRA; RAIZER; MEIRELLES, 2010).

A perspectiva popular nos cursos pré-universitários se efetiva também por meio de uma das principais estratégias adotadas pelos cursinhos populares nesse "duplo movimento", que é a inclusão de atividades voltadas à cultura e à cidadania. Muitos dos cursinhos populares trabalham no sentido de "formações para cidadania", "oficinas culturais" ou mesmo "disciplinas transversais" (MELLO, 2012, p. 
26), que, não raro, são realizadas em horários e espaços diferenciados. Em geral, as disciplinas da área das ciências sociais e humanas são as que mais facilmente abordam essas questões, o que se coloca como um desafio aos demais educadores, inclusive pela proposição de atividades interdisciplinares.

Uma das categorias centrais da educação popular é a conscientização; Paulo Freire, inclusive, publicou um livro dedicado a ela. Na obra, Freire (1979) esclarece que não é o autor desse vocábulo fundamental, atribui a responsabilidade a uma equipe de professores, entre eles Álvaro Pinto e Guerreiro, do Instituto Superior de Estudos Brasileiros, em meados de 1964. Quando ouviu pela primeira vez a palavra conscientização, Freire apreendeu a profundidade de seu significado, uma vez que desde aquele momento já assumia: "estou absolutamente convencido de que a educação, como prática da liberdade, é um ato de conhecimento, uma aproximação crítica da realidade" (1979, p. 25).

Para Freire, a realidade não se "dá aos homens como objeto cognoscível por sua consciência crítica", sendo necessária uma transição entre a apreensão espontânea da realidade para a apreensão crítica na qual a "realidade se dá como objeto cognoscível e na qual o homem assume uma posição epistemológica" (1979, p. 26). A realidade só pode ser modificada a partir da percepção por parte do homem de que isso é possível. Para ele, a "conscientização não pode existir fora da 'práxis', ou melhor, sem o ato ação - reflexão" (1979, p. 26); a conscientização, então, se constitui como um compromisso histórico.

Na perspectiva de Freire, a conscientização é necessária à emancipação, sobretudo coletiva, ainda que tenha uma dimensão individual, através da educação. Da mesma forma que busca o combate à "educação bancária", a educação popular vivenciada nos cursinhos populares promove o estímulo à problematização, ao diálogo e à relação horizontal professor-aluno. $\mathrm{O}$ educador popular deve valorizar os saberes dos educandos e reconhecer que o "saber de experiência feito" não deve ser ignorado nos processos educativos.

Num cursinho popular, a abordagem dos conteúdos deve ser planejada de forma que os conteúdos sejam trabalhados não apenas com o propósito de fazer “passar no vestibular", mas também de forma crítica (OLIVEIRA, 2011, p. 173), elemento que se coloca como um desafio a mais aos educadores que atuam nesses espaços. 


\section{0(A) educador(a) do Pupa vivenciando o princípio de indissociabilidade entre ensino, pesquisa e extensão}

A pesquisa, realizada entre 2015 e 2017, dedicou-se a compreender como se dá a articulação entre educação não formal e educação formal na relação entre o Pupa da UFSM e cursos superiores dos quais os(as) educadores(as) que atuam no projeto são oriundos(as). Seu desenvolvimento partiu da realização de uma reflexão sobre as bases teóricas e metodológicas da educação não formal e da educação popular, sua relação com os movimentos sociais e o surgimento dos cursos pré-vestibulares/ pré-universitários populares.

Para subsidiar a investigação, em nível de mestrado profissional em educação, foi realizada uma pesquisa exploratória, a fim de delinear o perfil dos educadores que atuaram no Pupa em 2016. Para esta fase exploratória, foi elaborado um questionário eletrônico com questões semiestruturadas, encaminhado por e-mail ao grupo de educadores(as) de 2016.

Como o problema de pesquisa envolveu uma atividade vivenciada por um grupo relativamente homogêneo de sujeitos, foram definidas como método de coleta de dados atividades em grupo, e, considerando as características do objeto de estudo e do público envolvido, escolheu-se a técnica de grupo focal. A opção pelos grupos focais se deu muito em função da similaridade com os círculos de cultura de Paulo Freire, uma vez que "o círculo de cultura dispõe as pessoas ao redor de uma 'roda de pessoas', em que visivelmente ninguém ocupa um lugar proeminente" (BRANDÃO, 2010, p. 69).

Além disso, o potencial formativo da interação proposta na pesquisa também se associa à definição de círculos de cultura elaborada por Brandão, pois "no círculo de cultura o diálogo deixa de ser uma simples metodologia ou uma técnica de ação grupal e passa a ser a própria diretriz de uma experiência didática centrada no suposto de que aprender é aprender a 'dizer a sua palavra"' (2010, p. 69). Assim, o grupo focal é um método utilizado com grupos de pessoas que passaram por uma experiência específica; nesse caso, muito mais do que um mecanismo de coleta de dados, o grupo focal se constitui, potencialmente, em um espaço de reflexão, reconhecimento de saberes construídos e ação em torno das aprendizagens vivenciadas no projeto, em especial as relacionadas à docência. De certa forma, busca-se a reinvenção dos círculos de cultura a partir da dialogicidade.

Após a realização dos grupos focais, procedeu-se a transcrição do conteúdo dos diálogos, e foi realizada a análise, embasada na técnica de análise de conteúdo proposta por Laurence Bardin (2011), dividida em três etapas: 1) pré-análise, 2) exploração do material e 3) tratamento do material e interpretações. Na pré-análise, 
foram identificadas algumas categorias recorrentes; na fase de exploração do material, foram sistematizadas as informações obtidas nos dois grupos e tecidas algumas interpretações, buscando fazer os cruzamentos com a base teórica utilizada; na etapa final, de tratamento do material, foram selecionados alguns trechos que serviram de base às interpretações relacionadas ao referencial teórico e às demais etapas da investigação.

A pesquisa realizada coloca o curso pré-universitário como um agente complementar na formação docente. Essa complementaridade se manifesta, sobretudo, no que se refere à prática da docência. Entretanto, mesmo os(as) educadores(as) que não estão se preparando para o magistério são favorecidos(as) pela atuação no Pupa. No caso dos licenciandos(as), a possibilidade de contato com o ambiente da sala de aula, mesmo em um espaço não formal de educação, complementa e ressignifica os conhecimentos obtidos no curso de formação. O diferencial, nesse sentido, é que, ao atuar como educador(a) no Pupa, o(a) estudante de graduação tem mais autonomia e liberdade para definir seu plano de trabalho do que em atividades orientadas e supervisionadas, realizadas dentro do curso.

Com base nas respostas ao questionário aplicado aos educadores em 2016, foi possível identificar um perfil básico predominante: feminino, branca, solteira, em início de formação em curso de bacharelado ou licenciatura, com pouco acesso a outros espaços de formação em educação popular e para a docência. Para a maioria dos participantes, a atuação como educador(a) ou monitor(a) no Pupa era a principal atividade relativa à prática de ensino.

Participou dos dois grupos focais realizados um total de seis educadores. No primeiro encontro, estiveram presentes dois educadores com formação em Letras (Letras Espanhol e Letras Português) e duas educadoras, uma bacharel em Biologia, que cursava mestrado em Zoologia Animal, e uma licencianda em Teatro; o tempo de atuação deles no projeto variava entre um e seis anos. Participaram do segundo encontro dois educadores, um cursando bacharelado e licenciatura em História, que atuava no projeto desde 2015, e uma graduanda do curso de Psicologia, que havia ingressado naquele ano no projeto. Seguindo diretrizes éticas para garantia de sigilo sobre a identidade dos participantes, foi adotado o seguinte esquema, para identificação das transcrições: participantes do primeiro grupo focal - AGF1, BGF1, CGF1 e DGF1; e participantes do segundo - AGF2 e BGF2.

Destacam-se alguns dados evidenciados pelas respostas ao questionário e relatados nos grupos focais, como a diversidade de educadores(as) no projeto, expressa em fatores como instituição de formação, idade, tempo de atuação e origem. Tal diversidade pode dificultar a construção de uma uniformidade ou sinergia no trabalho desenvolvido no cursinho, tendo como consequência impasses para atingir 
a meta de ser popular, quando nem todos os(as) educadores(as) trabalham nessa perspectiva.

Entretanto, essa mesma diversidade pode representar algo positivo, na medida em que a variedade de formação dos(as) educadores(as) e vivências anteriores e paralelas ao Pupa sejam trabalhadas na construção de trans(inter)disciplinaridade, o que depende também da predisposição de educadores(as) e equipes em trabalhar coletivamente na construção de atividades e materiais.

Ainda com relação à diversidade, ela foi apontada pelos participantes dos grupos focais como um dos desafios enfrentados no ingresso ao projeto. A expansão da rede pública e a universalização do acesso à escolarização impulsionaram um intenso debate em torno da diversidade na educação. Educar para a diversidade é um tema propalado amplamente no campo educacional, mas, na prática, os cursos de formação de professores(as) pouco avançaram, e ainda se estuda para ensinar alunos semelhantes, turmas homogêneas. Num espaço de educação popular como o Pupa, os(as) educadores(as) inevitavelmente se confrontam com a diversidade e, a partir dela, constroem suas estratégias de trabalho:

essa coisa de ter alunos de todas as idades e que tinha aluno esse ano... tinha alunos que sabiam tudo o que tu perguntava, o mais difícil eles te respondiam, e tinha alunos que eu tenho certeza que se sentiam muito constrangidos com isso. Como é que tu lida com isso? Como é que tu faz essa coisa? Tipo, não posso deixar de falar determinadas coisas, porque tem gente que sabe muito, mas eu também não posso aprofundar demais, porque tem gente que nunca viu isso; então, o que eu faço? Eu vou desmotivar de um lado, vou motivar do outro. Como que eu fico no meio termo? Pra mim isso é bem difícil assim (DGF1).

você sabe que tem alunos ali, e geralmente as experiências que a gente tem enquanto professor são em lugares em que os grupos são muito homogêneos, e aí você chega aqui e repara que na sua turma tem, às vezes, uma aluna de 4050 anos do lado de um aluno de 16 anos, e depois de um tempo até comecei a aumentar os exemplos, né? Daí tu chega numa turma que tem um aluno que lê Marx, que lê o Capital, e tem outro aluno que é quase analfabeto; então, geralmente tem esse impasse de o que que eu faço agora? $\mathrm{E}$ a gente não sabe exatamente o que fazer, a gente acaba fazendo aquele modelo tradicional de aula, nem tanto da nossa formação enquanto professor num curso de licenciatura, mas aquela formação que é anterior e inconsciente, de quando a gente é aluno, né? E até a gente perceber que isso - não é que funcione ou não funcione - é que isso soa meio estranho num lugar como esse, é meio que perder potencial às vezes de alunos, né? Até tu perceber que você pode continuar trabalhando enquanto um educador, enquanto um professor... (AGF1).

Esse "confronto" com o diferente pode ser considerado um aspecto positivo e, até mesmo, um diferencial ao(à) educador(a) que atua em espaços de educação popular em relação a educadores(as) que tiveram apenas a formação acadêmica. A diversidade é apontada tanto em relação às faixas etárias dos(as) educandos(as) quanto em relação aos conhecimentos prévios não necessariamente relacionados à escolarização. Nesse ponto, os(as) educadores precisam exercitar alguns elementos 
constituintes da educação popular de Paulo Freire, como a valorização do "saber de experiência feito" (saberes cotidianos, espécie de senso comum), e criar estratégias que lhes permitam trabalhar com essa diversidade.

Os(As) educadores(as) apontaram como desafio inicial da atividade no projeto a compreensão dos princípios da educação popular, como se observa nas passagens a seguir:

é um desafio trabalhar a teoria dentro de um espaço de educação popular dando a ela um valor de uso (BGF1).

um desafio que eu senti durante bastante tempo na minha entrada aqui no Alternativa é que, quando você vem pra cá, você não sabe muito bem o que é essa educação popular, mas ao mesmo tempo você percebe que esse é um lugar diferente, você não sabe exatamente por que, geralmente, num primeiro momento, tu percebe que os alunos são diferentes e aí tu não sabe exatamente o que que é pra você fazer, né? (AGF1).

Esse desafio inicial envolve duas questões principais: o desconhecimento sobre educação popular e atuação nessa perspectiva e os estereótipos ligados à formação e à trajetória escolar. Entre os estereótipos herdados da trajetória escolar, estão a necessidade de "vencer o conteúdo", muitas vezes priorizado em detrimento do aprendizado na educação formal, e a noção de que só se está “preparado(a)" para ensinar quando se conclui o curso de formação ou, ao menos, se avança mais no curso.

a grande dificuldade que eu tenho é de fazer alguma coisa que não seja o "decorem isso, vai cair na prova". Como que eu tiro isso? Que não é exatamente pra isso que a gente tá aqui, apesar de ser pra isso que vocês estão aqui. Como que eu faço pra lidar com isso? (DGF1).

tem algo interessante também: que tô aqui no meu segundo ano vai fechar, né? E ainda não me sinto segura pra fazer algumas coisas, e como isso é louco. Esse espaço tá aqui, os alunos estão aqui, e eu ainda tenho muito medo de propor algumas coisas (CGF1).

por muito tempo eu tive uma resistência em vim pra cá, por não me sentir pronta e por não ter domínio dessas questões que, com o tempo eu fui entender, que não eram, não era a proposta que eu deveria trazer pra cá, por não condizer com a proposta de educação popular (BGF2).

eu acho que todo mundo passa por esse processo quando entra, pelo menos no Alternativa, que é aquele "o que é que eu tenho para contribuir com as pessoas?", "será que eu tenho algo a contribuir?”. Eu entrei no terceiro semestre, tu também, né? Então, tu tá muito no início do curso, tu tá muito entendendo que caminhos tu vai andar dentro do próprio curso, tipo: pensar em contribuir algo num espaço de educação já é algo muito além disso, né? Então, é isso que tu fica se perguntando, e era isso o meu dilema e eu conversava com as pessoas mais antigas. Então, eu acho que essa foi a primeira barreira pra mim e também a primeira revelação: que tu entra aqui tu aprende muito mais às vezes do que tu ensina, do que tu passa pra alguém, né? E é essa... quando cai a ficha disso, assim, é muito legal, sabe? Talvez. Tipo, e isso não é errado, né? Tipo, tu também pensar em tá aqui pelo teu próprio crescimento: enquanto educador, enquanto profissional na área de Psicologia, ou o que quer que seja, né? Eu acho que essa é/foi a minha primeira barreira, sem dúvida (AGF2). 
A educadora do primeiro excerto manifesta ainda o conflito gerado pela prática no Pupa em relação às crenças em torno do aprender e a dificuldade em superar a imposição da memorização. Outros pontos a destacar nesse excerto são o conflito na preparação para o Exame Nacional do Ensino Médio e a perspectiva da educação popular: isso se evidencia na passagem "Como que eu tiro isso? Que não é exatamente pra isso que a gente tá aqui, apesar de ser pra isso que vocês estão aqui. Como que eu faço pra lidar com isso" (DGF1).

A segunda educadora expõe a dificuldade em se desvencilhar dos modelos pré-estabelecidos de práticas e, embora o espaço do projeto seja propício à experimentação, relata: "ainda tenho muito medo de propor algumas coisas" (CGF1).

$\mathrm{O}$ relato da educadora da equipe de Psicologia reforça a pressão para avançar no curso antes de "ir a campo", antes de se colocar em contato com o público, nas palavras dela: "eu tive uma resistência em vim pra cá por não me sentir pronta" (BGF2). Entretanto, a mesma educadora informa, em outra passagem, o quão positiva foi essa inserção no projeto em relação à sua postura frente ao curso:

me mudou bastante sim, mudou a forma como... A minha postura em aula, então as contribuições que eu trago pra aula assim, eu senti como muito mais abertas, muito mais múltiplas, plurais, né? Não só do "ah, pode ser esse quadro", "pode ser essa patologia”, "pode ser isso ou aquilo", mas... Enfim, muito mais humanizado e... E o próprio aproveitamento das disciplinas em si, porque quando eu entrei aqui no Alternativa, no terceiro semestre, eu tava tendo a cadeira de Psicologia Comunitária e Psicologia e Escola, então, mudou muito a forma como eu via essas duas disciplinas, pra além do teórico. Então as professoras tavam falando, e eu conseguia fazer links diretos (BGF2).

O exemplo da educadora de Psicologia é pontual, em função das disciplinas cursadas no curso de Psicologia. Outros educadores relatam situação semelhante com relação a conteúdos ou disciplinas, como se observa no excerto a seguir:

eu consegui perceber algumas, alguns pontos positivos e principalmente negativos na área da pesquisa na academia que eu... Até então, eu não percebia e que eu vi que muitas pessoas que não tiveram essa aproximação com o Alternativa... Eles deixavam passar (AGF2).

Essas passagens indicam que a atuação no Pupa, que é uma ação de extensão, pode suscitar aprendizagens atribuídas até o momento apenas ao ensino, tornando a formação desses(as) estudantes ainda mais ampla. Um aspecto observado ao longo da pesquisa foi o desenvolvimento da criticidade em relação à própria formação e à organização curricular dos cursos de licenciatura (e de bacharelado), constatado por meio dos grupos focais. Os(As) educadores(as) que participaram dos grupos focais apontaram elementos que consideram falhos na organização curricular ou na forma de abordagem dos conteúdos, especialmente no que se refere à relação teoria-prática, praticamente restrita às disciplinas Didática e Prática de Ensino, geralmente ofertadas nos períodos finais dos cursos de licenciatura. 
Destacam-se nos grupos focais algumas críticas feitas ao currículo dos cursos de graduação, em especial, dos cursos da área designada ciências exatas, relativas ao predomínio de disciplinas teóricas e à consequente crença de que "o que importa é o conteúdo": "a grande dificuldade que eu tenho é de fazer alguma coisa que não seja o 'decorem isso, vai cair na prova', como que eu tiro isso? Que não é exatamente pra isso que a gente tá aqui” (DGF1).

Percebe-se que, mesmo em um espaço não formal e de educação popular, como o Alternativa, algumas crenças oriundas da educação formal se impõem e agem como barreiras para o trabalho dos(as) educadores(as). Em outros momentos, foi relatada a ausência ou a limitação de espaços dentro do curso de graduação para o(a) estudante se colocar na posição de professor(a), aprender a pensar como professor(a):

a formação do professor deveria ser distribuída por todas as disciplinas, né? Eu lembro que, na minha graduação, eu tenho muito carinho por dois professores em duas disciplinas, assim, ó, que foram pouquíssimos, né? Em que, por exemplo, a prova da disciplina tinha uma questão, assim, que exigia de ti determinado conhecimento específico, mas você, já no papel de professor, né? Uma das questões até eu sempre guardei pra mim, né! "Você trabalhou conteúdo tal que falou tal coisa para os alunos. Tal aluno teve tal dúvida, tal problema aconteceu. No final do semestre, a mãe do determinado aluno veio tomar satisfações de você a respeito de tal coisa, tal coisa e tal coisa. Como você, enquanto professor do tal aluno, responderia esses pais?", né? Foi o mais próximo assim de uma reflexão de "olha, você já é um professor" em formação, né? Continuamente em formação, né? Permanentemente em formação. Isso é muito raro nos cursos (AGF1).

$\mathrm{O}$ relato do educador parece singelo, mas expressa a carência da perspectiva da formação para a docência recorrente nos cursos de formação, mesmo nas licenciaturas. Ainda sobre as configurações curriculares, em especial, o espaço da prática restrito às disciplinas Prática de Ensino e Didática, os educadores avaliam que as demais disciplinas deveriam assumir parte dessa tarefa:

aí vem a questão de os professores dos cursos de licenciatura, de uma maneira muito mesquinha e muito perversa... Deixam tudo acumular para o estágio, e aí fica aquela coisa, assim, de professora de estágio ou o professor do estágio que dane-se, né? Isso, a formação do professor, deveria ser distribuída por todas as disciplinas, né? (AGF1).

Apesar do que foi relatado e reiterado pelos(as) educadores(as), consta nas Diretrizes Curriculares Nacionais para a Formação de Professores uma orientação diferente da vivenciada, pois, de acordo com a resolução Conselho Nacional de Educação/Conselho Pleno (CNE/CP), que institui as Diretrizes Curriculares Nacionais para a Formação de Professores da Educação Básica, em nível superior, curso de licenciatura, de graduação plena: 
Art. 12. Os cursos de formação de professores em nível superior terão a sua duração definida pelo Conselho Pleno, em parecer e resolução específica sobre sua carga horária.

$\S 1^{\circ}$ A prática, na matriz curricular, não poderá ficar reduzida a um espaço isolado, que a restrinja ao estágio, desarticulado do restante do curso.

$\S 2^{\circ}$ A prática deverá estar presente desde o início do curso e permear toda a formação do professor.

$\S 3^{\circ}$ No interior das áreas ou das disciplinas que constituírem os componentes curriculares de formação, e não apenas nas disciplinas pedagógicas, todas terão a sua dimensão prática (BRASIL, 2002, p. 5).

Como se percebe na legislação, caberia ao curso de licenciatura a oferta de meios de contato com a área de atuação antes da realização do estágio, e a dimensão prática deveria estar presente também nas demais disciplinas, tal como sugere um educador:

os programas, eles são pensados para que as demais disciplinas também tenham a sua própria carga horária de didática e formação de professores, digamos assim, né? Só que isso não é efetivado. Se uma disciplina tal, sei lá, sobre os passarinhos, né? Tu tem essa parte de tu aprender pra ti sobre os passarinhos, né? Nessa disciplina, já deveria ser trabalhada em parte, né? Em algum momento, essa questão de "não, agora você é o professor dos passarinhos", professor sobre passarinhos ou alguma coisa assim, né? Então, isso deveria ser melhor distribuído ao longo da graduação, né? (AGF1).

As impressões dos(as) educadores(as) relatadas nos grupos focais indicam elementos que podem ser adotados no sentido de aprimorar os cursos de licenciatura, como todas as disciplinas "assumirem" que se está formando para a docência. Com relação ao estágio, por exemplo:

[...] essas cargas horárias de estágios, né? Didáticas, elas são pequenas e curtas, né? Dependendo do teu critério de avaliação... mas por que, os programas, eles são pensados para que as demais disciplinas também tenham a sua própria carga horária de didática e formação de professores, digamos assim, né? Só que isso não é efetivado (AGF1).

Aponta-se o papel dos cursos pré-universitários e demais espaços educacionais na construção da identidade do(a) professor(a)/educador(a):

talvez um curso pré-universitário popular seja mais longitudinal, né? Você continuamente vai vendo situações que te fazem repensar... e, aí sim, tu tem realmente uma formação continuada, permanente. Eu também nunca entendi muito bem essa expressão formação continuada, porque: qual é o professor que não tá continuamente em formação? Qual o educador que já tá acabadinho, né? Fechou tudo, né? Chegou no último nível do vídeo game e não tem mais um (AGF1).

O educador reitera a perspectiva da formação do(a) professor(a) como contínua e destaca a possibilidade de se colocar na posição de professor(a)/educador(a) 
no espaço do pré-universitário. Uma constatação recorrente dos(as) educadores(as) expressa nos grupos focais é a de que o(a) licenciando(a) raramente é visto como "um(a) professor(a) em formação", da mesma forma como o(a) estudante de Psicologia também não é visto(a) como "um(a) psicólogo(a) em formação"; mas, em espaços como o Alternativa, eles(as) têm a possibilidade de se colocar nessa posição, de se experimentar. Dessa forma, o Alternativa exerce o papel de agente complementar na formação desses(as) universitários(as), oferecendo a eles e a elas uma possibilidade de prática diferenciada.

As impressões relatadas pelos(as) participantes dos grupos focais incluem, ainda, aprendizagens diversificadas, como a iniciação à pesquisa e a inserção na militância em favor da educação popular e de outras demandas estudantis.

Apesar da constatação do Pupa como agente complementar na formação dos educadores, fica clara a necessidade de se criarem mecanismos voltados ao aumento da adesão efetiva dos(as) educadores(as) ao projeto, fator que encaminhou a elaboração de dois "produtos"3: um plano de atividades e um parecer de atividades, a exemplo do que ocorre com outras atividades complementares nos cursos de graduação. Sugeriu-se que essa documentação fosse apresentada pelos(as) educadores(as) em seus cursos de origem, juntamente com o certificado de participação no projeto, a fim de pleitear horas de atividade complementar de graduação ou endossar a realização de observações no projeto, por exemplo.

\section{Considerações finais}

A reflexão proposta considera a extensa universitária uma "via de mão dupla", ou seja, ao mesmo tempo em que permite à instituição universitária uma ampliação de horizontes pela inserção na comunidade, também potencializa a ressignificação do cotidiano para pessoas que, em muitos casos, não tiveram oportunidade de prolongamento de seus estudos. Portanto, é na troca e na partilha de experiências e saberes que reside a fecundidade da extensão como princípio universitário com a pesquisa e o ensino.

Nesse sentido, o pensamento pedagógico de Paulo Freire segue atual, ao provocar o debate sobre a extensão como "comunicação", sinalizando os compromissos sociais das universidades com a "palavra" daqueles e daquelas que se envolvem e constituem a trama social. Recupera-se, assim, a noção de práxis, na qual se estabelece uma relação sinérgica entre teoria e prática.

Mesmo diante das contradições da relação entre a universidade e a comunidade, expressas no histórico elitista da instituição, inúmeras ações integram projetos que são desenvolvidos no intuito de realizar a "via de mão dupla", trazendo ganhos 
para todos e todas. Um exemplo significativo é encontrado em projetos de cursinhos pré-universitários populares, originalmente chamados de pré-vestibulares populares, um fenômeno presente no cenário educacional brasileiro, que ganhou ênfase a partir do processo de redemocratização dos anos 1980.

Em termos freireanos, os cursinhos populares fazem a denúncia do elitismo das universidades e anunciam uma ação concreta, com vistas à ampliação das oportunidades educacionais. Numa sociedade desigual como a brasileira, o acesso a níveis superiores de estudo potencializa processos de mobilidade social ascendente, podendo gerar efeito tanto econômico como cultural.

A pesquisa desenvolvida no Pupa da UFSM mostra que o protagonismo discente é uma aposta formativa viável e altamente positiva. A formação universitária tem um componente profissionalizante, mas deve ser algo além disso. $\mathrm{O}$ desenvolvimento de posturas éticas, cidadãs e comprometidas com a construção de uma sociedade mais justa é uma tarefa nobre de que o ambiente acadêmico deve se ocupar. Afinal, a sensibilidade social não é incompatível com o rigor científico, muito pelo contrário, pois aprendemos com a pedagogia freireana que o caráter político da educação nos exige formação séria e com rigor metódico.

Potencializar a formação inicial de professores(as) em nossas universidades é um desafio inadiável. Os grupos focais realizados com estudantes universitários(as) da região de Santa Maria sugerem as necessidades de represarmos os currículos acadêmicos e valorizarmos práticas formativas além da sala de aula, indo ao encontro da meta de no mínimo $10 \%$ de atividades de extensão nos cursos de graduação, prevista no PNE (2014-2024).

As experiências de cursos pré-universitários populares em geral, e a do Pupa da UFSM em específico, demonstram a importância de as instituições universitárias assumirem essas iniciativas como projetos/programas de extensão, dando o suporte necessário ao desenvolvimento do trabalho. A universidade assume uma função social importante e contribui na preparação dos segmentos populares para a continuidade dos estudos.

$\mathrm{Na}$ fronteira entre os espaços formais e não formais de educação, da ciência e da militância, os cursos pré-universitários populares sugerem que são viáveis práticas de educação popular no ambiente acadêmico. Em outras palavras: o centenário sonho de Córdoba é não só possível, como também uma realidade que contribui para que novos capítulos da relação entre universidade e comunidade sejam escritos. 


\section{Notas}

1 Observa-se que se encontra na literatura especializada os termos "educação superior" e "ensino superior" tratados, via de regra, como sinônimos, ainda mais se ampliarmos o debate em perspectiva internacional. Mesmo considerando as nuances conceituais dos termos em tela, adota-se nesse estudo sua indiferenciação, pois entende-se que se referem aos estudos superiores em instituições legalmente apropriadas para esse fim (universidade, centro universitário, instituto superior, faculdade).

2 Os dados relativos às metas do PNE podem ser acompanhados pelos canais oficiais do Governo Federal (INEP) e pelo Observatório do PNE, organização sintomática do interesse de grupos privados pela educação no Brasil. Agrupados em torno da Organização Não Governamental (ONG) “Todos pela Educação”, as entidades empresarias procuram participar ativamente do debate educacional, inclusive com assessorias a governos. Maiores informações em <https://www.todospelaeducacao.org.br/>. Acesso: 06 fev. 2018.

3 O "produto" é caracterizado, nos mestrados profissionais, como um diagnóstico e/ou uma intervenção em um problema concreto que permeia $(\mathrm{m})$ a prática profissional. Representa, assim, uma perspectiva aplicada de ciência, buscando enfrentar questões que desafiam profissionais de determinada área.

\section{Referências}

BRASIL. Notas estatísticas do Censo da Educação Superior 2016. Brasília: Instituto Nacional de Estudos e Pesquisas Educacionais Anísio Teixeira (INEP), 2017. Disponível em: <http://download.inep.gov.br/educacao_superior/censo_superior/apresentacao/2014/coletiva_censo_superior_2013.pdf>. Acesso em: 22 abr. 2017.

. Constituição da República Federativa do Brasil de 1988. 1988. Disponível em: <http:// www.planalto.gov.br/ccivil_03/constituicao/constituicao.htm>. Acesso em: 06 fev. 2018.

Ministério da Educação, Conselho Nacional de Educação. Resolução CNE/CP01, de 18 de fevereiro de 2002 - Institui Diretrizes Curriculares Nacionais para a Formação de Professores da Educação Básica, em nível superior, curso de licenciatura, de graduação plena. Disponível em: <http://portal.mec.gov.br/cne/arquivos/pdf/rcp01_02.pdf>. Acesso em: 28 jan. 2017.

BARDIN, Laurence. Análise de conteúdo. São Paulo: Edições 70, 2011.

BRANDÃO, Carlos Rodrigues. O que é educação. São Paulo: Abril Cultura; Brasiliense, 1985.

. Círculo de Cultura. In: STRECK, R. Danilo; REDIN, Euclides; ZITKOSKI, Jaime José (Org.). Dicionário Paulo Freire. 2. ed. rev. e ampl. Belo Horizonte: Autêntica, 2010. p. 69-70.

CUNHA, L. A. A universidade temporã: o ensino superior da colônia à Era Vargas. Rio de Janeiro: Francisco Alves, 1985.

FLEURI, Reinaldo Matias. Conversidade: extensão universitária e movimentos sociais. In: FIOREZE, Cristina; MARCON. Telmo (Org.). O popular e a educação: movimentos sociais, políticas públicas e desenvolvimento. Ijuí: Editora Unijuí, 2009. p. 85-130.

FREIRE, Paulo. Conscientização: teoria e prática da libertação: uma introdução ao pensamento de Paulo Freire. São Paulo: Cortez \&Moraes, 1979.

Extensão ou comunicação? 7. ed. Rio de Janeiro: Paz e Terra, 1983.

GADOTTI, Moacir. A questão da educação formal/não-formal. In.: INSTITUT INTERNATIONAL DES DROITS DE L'ENFANT. Droit à l'education: solution à tous les problèmes sans solution? 
Sion: Institutinternacional des droit de l'Enfant c/o Institut Universitaire Kurt Bösch, 2005. p. 91-108. Disponível em: <http://www.vdl.ufc.br/solar/aula_link/lquim/A_a_H/estrutura_pol_ gest_educacional/aula_01/imagens/01/Educacao_Formal_Nao_Formal_2005.pdf >.Acesso em: 15 mar. 2018.

GOHN, Maria da Glória Marcondes. Educação não formal e cultura política. 5. ed. São Paulo: Cortez, 2011.

.Educação não formal e o educador social: atuação no desenvolvimento de projetos sociais. São Paulo: Cortez, 2010.

. Educação não-formal, participação da sociedade civil e estruturas colegiadas nas escolas. Ensaio: Avaliação e Políticas Públicas em Educação, Rio de Janeiro, v. 14, n. 50, p. 11-25, 2006.

MACIEL, Jarbas. A fundamentação teórica do Sistema Paulo Freire. Revista de Cultura da Universidade do Recife, Recife, n. 4, p. 25-58, abr./jun. 1963.

MELLO, Marco. A hora da onça beber água: identidade e projeto político-pedagógico dos cursos pré-vestibulares populares. In: PEREIRA, Vilmar Alves; BORGES, Daniele Simões; SOUZA, Neusiane (Org.). Ventos que sopram do sul: vivências de educação popular e transformação social no PAIETS-FURG. Rio Grande, RS: Editora da FURG, 2012. p. 13-44.

OLIVEIRA, Elizabeth Serra de. Movimentos sociais e novas abordagens da Educação Popular Urbana. Contexto \& Educação, Ijuí, a. 26, n. 85, p. 157-176, jan./jun. 2011.

PAULA, João Antônio de. A extensão universitária: história, conceito e propostas. Interfaces Revista de Extensão, Belo Horizonte, v. 1, n. 1, p. 5-23, jul./nov. 2013.

PEREIRA, Thiago Ingrassia; RAIZER, Leandro; MEIRELLES, Mauro. A luta pela democratização do acesso ao ensino superior: o caso dos cursinhos populares. Espaço Pedagógico, Passo Fundo, v. 17, p. 86-96, 2010.

PINTO, Álvaro Vieira. A questão da universidade. 2. ed. São Paulo: Cortez, 1994.

ROMANELLI, Otaíza de Oliveira. História da educação no Brasil (1930 / 1973). 37. ed. Petrópolis, RJ: Vozes, 2012.

ROSSATO, Ricardo. Universidade: nove séculos de história. 2. ed. Passo Fundo: UPF Editora, 2005.

SANTOS, Boaventura de Sousa. Universidade no século XXI: para uma reforma democrática e emancipatória da universidade. 2. ed. São Paulo: Cortez, 2005a.

O Fórum Social Mundial: manual de uso. São Paulo: Cortez, 2005b.

Para uma sociologia das ausências e uma sociologia das emergências. In: SANTOS, Boaventura de Sousa (Org.). Conhecimento prudente para uma vida decente. São Paulo: Cortez, 2004. p. 777-821.

SGUISSARDI, Valdemar. Universidade no Brasil: dos modelos clássicos aos modelos de ocasião? In: MOROSINI, Marília Costa (Org.). A universidade no Brasil: concepções e modelos. 2. ed. Brasília: Inep, 2011. p. 275-289.

ZAGO, Nadir. Cursos pré-vestibulares populares: limites e perspectivas. Perspectiva, Florianópolis, v. 26, n. 1, p. 149-174, jan./jun. 2008. 